\title{
Working Mechanism of OATSCB-CFST Joint
}

\author{
Li Ming \\ Civil Engineering College \\ Shenyang Jianzhu University \\ Shenyang, China \\ Jangho Group Co., Ltd. \\ Beijing, China \\ e-mail: dingxianxing@126.com \\ Wen Yuting \\ Civil Engineering College \\ Shenyang Jianzhu University \\ Shenyang, China \\ e-mail:517950254@qq.com \\ Wang Yuanqing \\ Civil Engineering College \\ Tsinghua University \\ Beijing, China \\ e-mail: wang-yq@mail.tsinghua.edu.cn
}

\begin{abstract}
Concrete filled steel tube (CFST) and steel castellated beam are ideal components in the structure. However the research about the connection of them is less at present. In order to analyze the working mechanism of outer annular-stiffener type steel castellated beamconcrete filled steel tube (OATSCB-CFST) joint, loadbearing process of this type of middle column joints under low cycle load are simulated by finite element software. Before simulating, the simulation method is verified by the test data of a middle joint of outer annular-stiffener type steel solid beam-concrete filled steel tube (OATSB-CFST). The results show that: the high stress area of the OATSCB-CFST joint is mainly focused on the position of the castellated beam and the annular-stiffener near the border between them, the position of the tube near annular-stiffener, the position of the annular-stiffener near medial axis of the steel beam, and the position of the core zone concrete. This implies that the annular-stiffener zone should be a key consideration in the design.
\end{abstract}

Keywords- CFST; Steel Castellated Beam; beamcolumn joint; force behavior;working mechanism.

\section{INTRODUCTION}

Concrete filled steel tubular (CFST) is made of steel tube filled with concrete. It has high bearing capacity, plasticity and toughness, and it is easy to be constructed, so it has been widely used in engineering [1]. Steel Castellated Beam (SCB) is made of wide flange steel H-beam or I-beam with castellated holes, which can save steel and is convenient in construction for the pipelines can pass-through the castellated holes and etc. And SCB also has been widely used in civil engineering [2]. Especially due to outer annularstiffener earthquake, due to the constraints effect of the

\author{
Tao Wei \\ Jangho Group Co., Ltd. \\ Beijing, China \\ e-mail: taowei@jangho.com \\ Wang Bin \\ Jangho Group Co., Ltd. \\ Beijing, China \\ e-mail: wangbin06@jangho.com \\ Shan Renliang \\ Civil Engineering and Mechanics \\ China University of Mining\&Technology \\ Beijing, China \\ e-mail: srl@cumtb.edu.cn
}

steel tube, the inner concrete will not be peeled or cracked, which made the superior compressive performance of concrete and good tensile properties of the steel tube played enough. So CFST has excellent seismic performance and is easy to realize the project of "strong column". At the same time, because the castellated holes of SCB exist near to the neutral axis, which reduce the elastic bending modulus of the crosssection a little but reduce the inelastic bending modulus of cross-section larger. When the earthquake happened, SCB is easier to enter into plastic and to form "weak beam" yielding mechanism. In all, CFST and SCB are ideal components in civil engineering. Therefore, it becomes one of the focuses of civil engineers that how to connect them together and how the force behavior of the connected joint is. But little study is done on it. So, in this paper, the force behavior of OATSCB-CFST would be analyzed.

\section{FINITE ELEMENT SIMULATION AND ITS VERIFICATION OF OATSCB-CFST JOINT}

According to the form of OATSB-CFST joint [3-4], the OATSCB-CFST joint is designed as Fig .1.The loading process of the OATSCB-CFST joint is simulated with ABAQUS which is a kind of finite element software. The loading device schematic diagram is shown as Fig .2. In simulation: the stressstrain curve of SCB and steel tube are used with the elastic-plastic material model; the stress- strain curve of the core concrete is plastic damage model; S4 shell elements are used to simulate Steel tube and SCB; eight-node reduced integration of the three- 
dimensional solid elements (C3D8R) are used to simulate the core concrete and loading plate. The default hard contact is used to simulate the normal direction of the contact between steel tube and concrete, and the tangential coulomb friction model is used, in which, the friction coefficient is taken as 0.6 from reference[5]. The upper and lower end of the steel column is hinged by only binding the displacement of $y$-direction. In order to avoid stress concentration, the concentrated force is transformed into surface load. Ant-symmetric low cyclic loading is applied on both ends of beam-end. And we use Newton-Raphson iteration method to solve it. In order to test the validity of the simulation method, the loading process of the OATSB-CFST member in reference [6] is simulated by above method, because no test has been done on OATSCB-CFST joint before. The skeleton curves between simulation and

experiment are shown as Fig .3. It can be seen from Fig .3, the result of simulation and test are similar to each other. So, it has a certain rationality that this kind of finite element simulation method can be used to study force behavior of the OATSCB-CFST.

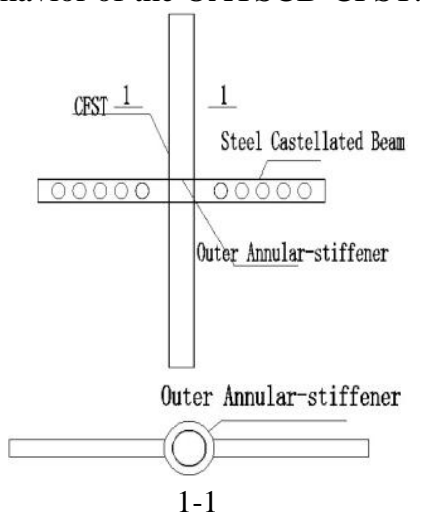

Figure 1. Schematic structure of OATSCB-CFST

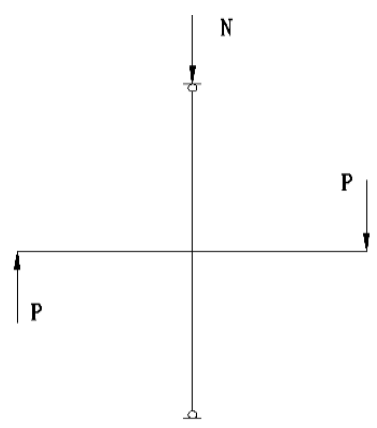

Figure 2. Loading device schematic diagram

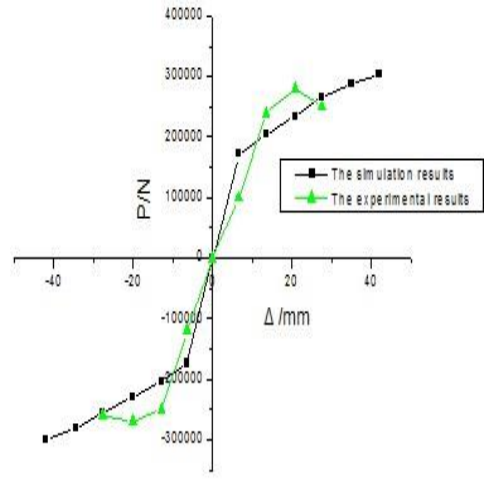

Figure 3. Skeleton curves Comparison

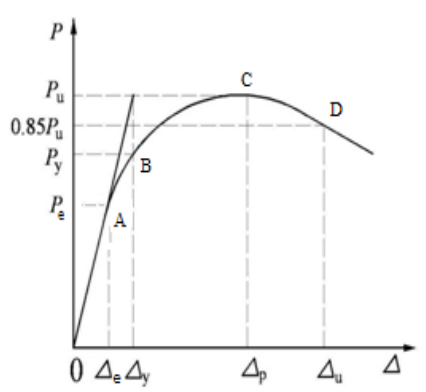

Figure 4. Schematic diagram of the P- $\Delta$ skeleton curve

\section{WORKING MECHANISM OF OATSCB-CFST}

In order to analyze the force behavior of OATSCBCFST joint, a scaled OATSCB-CFST joint is designed and the corresponding three-dimensional solid finite element model is established. At the same time, a OATSB-CFST with the same size is also designed and the corresponding 3D finite element model is also established. The specific dimensions are as follows: the diameter of CFST is $200 \mathrm{~mm}$, the steel tube wall thickness is $5 \mathrm{~mm}$; the height of CFST is $2200 \mathrm{~mm}$; the length of SCB is $1100 \mathrm{~mm}$; the cross-section height of SCB is $150 \mathrm{~mm}$; the width of the flange is $100 \mathrm{~mm}$; the thickness of web plate is $6 \mathrm{~mm}$; the thickness of the flange is $8 \mathrm{~mm}$; the SCB hole is round hole; the circle is on the centerline of SCB, the diameter of the hole is $100 \mathrm{~mm}$; the first hole from the column edge is $200 \mathrm{~mm}$; the distance or the holes are $160 \mathrm{~mm}$; the outer annularstiffener width is $50 \mathrm{~mm}$ and its thickness is $8 \mathrm{~mm}$. In simulation, the axial compression ratio is 0.4 at the head of column.

In order to analyze the working mechanism of OATSCB-CFST joint, we extract its mises stress nephogram in concrete, tube and SCB of points A,B,C,D which are on the envelope curve of the loaddisplacement hysteresis curve (P- $\Delta$ skeleton curve for short ). P- $\Delta$ skeleton curve is showed as Fig .4, in which, $\mathrm{P}$ represents the load applied on the beam end, $\Delta$ represents the displacement on the beam end, $\mathrm{Pe}$ represents its proportional limit, Py represents its yield 
load, $\mathrm{Pu}$ represents its ultimate load, $\Delta \mathrm{e}$ represents the displacement of its proportional limit, $\Delta y$ represents the displacement of its yield load, $\Delta \mathrm{p}$ represents the displacement of its ultimate load, $\Delta \mathrm{u}$ represents the displacement of $85 \%$ ultimate load. Mises stress nephogram is showed in Fig .5 to Fig .7, in which the unit for stress is Mpa. The mises stress nephograms of concrete are showed in Fig .5, concluding a nephogram of the whole column, nephograms of the sections of the column where the outer annular-stiffeners are, a nephogram of radial section of the column.

From Fig .5-Fig .7, it can be seen that the high stress area of the OATSCB-CFST joint is mainly focused on the position of the castellated beam and the annular-stiffener near the border between them, the position of the tube near annular-stiffener, the position of the annular-stiffener near medial axis of the steel beam, and the position of the core zone concrete. This implies that the annular-stiffener zone should be a key consideration in the design.

\section{CONCLUSION}

Based on the above analysis, the following conclusions can be obtained:

The high stress area of the OATSCB-CFST joint is mainly focused on the position of SCB and the annular-stiffener near the border between both, the position of the tube near annular-stiffener ,the position of the annular-stiffener near SCB's medial axis, and the position of the core zone concrete.

The joint in the position of the border between SCB and outer annular-stiffener lose efficacy firstly. The high stress area is mainly focused on the area near

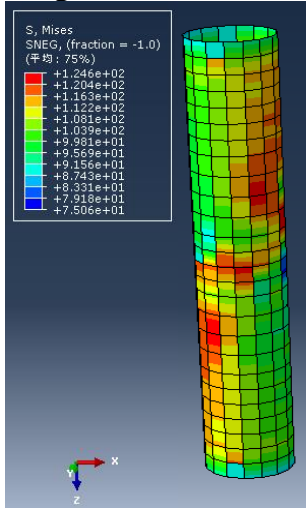

(a) Stress nephogram of the steel tube at point $\mathrm{A}$

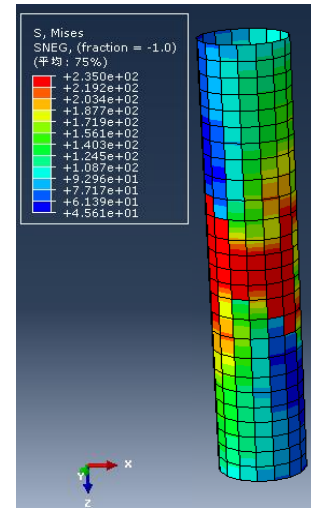

(b) Stress nephogram of the steel tube at point $B$ the border between outer annular-stiffener and SCB, and the tube near the outer annular-stiffener.

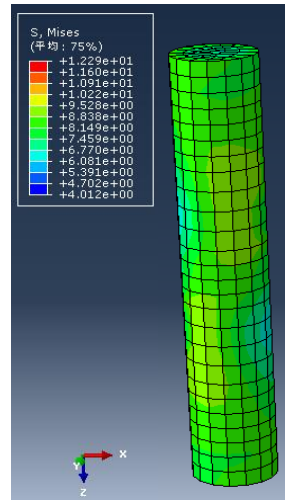

(a) Stress nephogram of the concrete at point $\mathrm{A}$

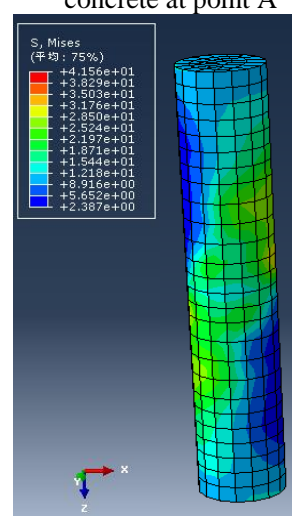

(c) Stress nephogram of the concrete at point $\mathrm{C}$

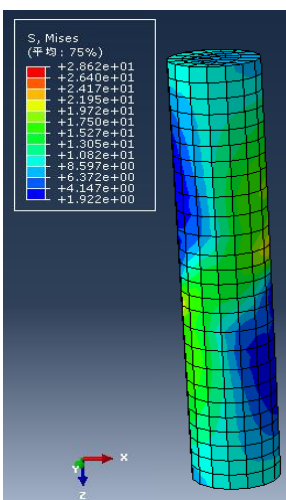

(b) Stress nephogram of the concrete at point $\mathrm{B}$

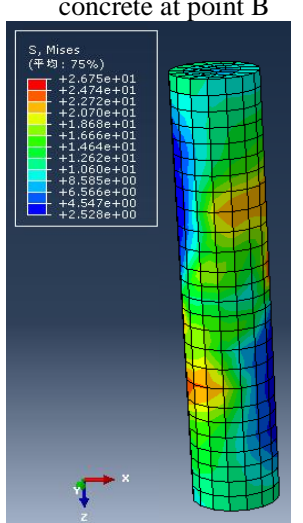

(d) Stress nephogram of the concrete at point $\mathrm{D}$
Figure 5. Stress nephogram of the concrete corresponding to the different points of the P- $\Delta$ skeleton curve

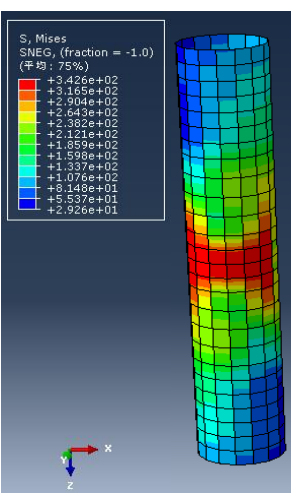

(c) Stress nephogram of the steel tube at point $\mathrm{C}$

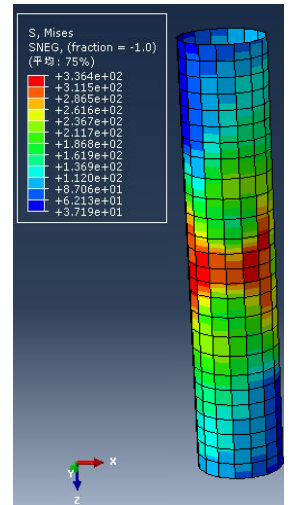

(d) Stress nephogram of the steel tube at point $\mathrm{D}$
Figure 6. Stress nephogram of the steel tube corresponding to the different points of the P- $\Delta$ skeleton curve 


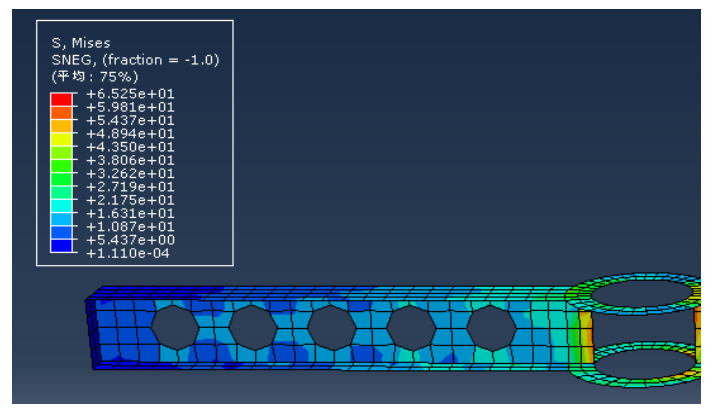

(a) Stress nephogram of the SCB at point A

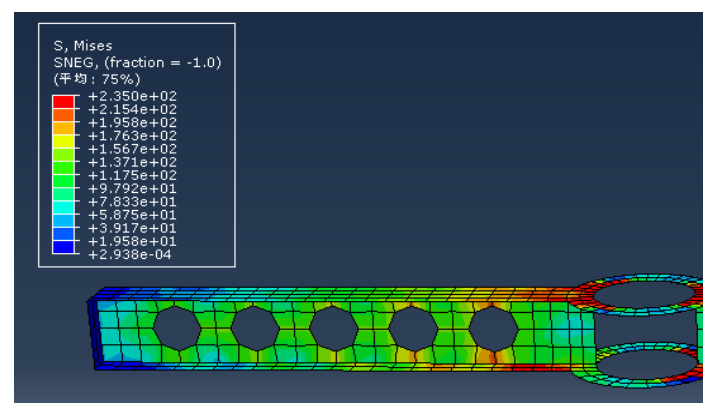

(b) Stress nephogram of the SCB at point B

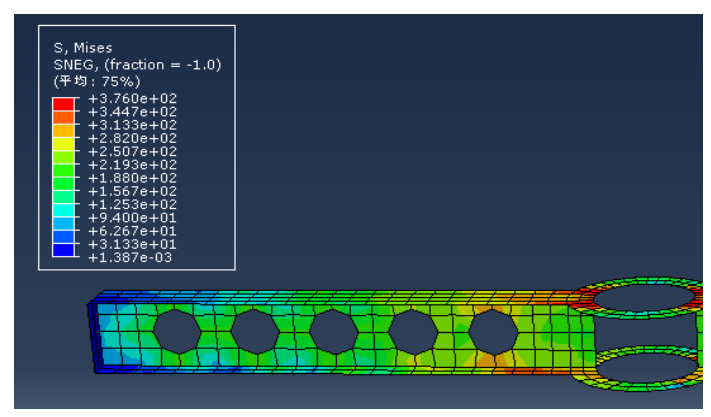

(c) Stress nephogram of the SCB at point C

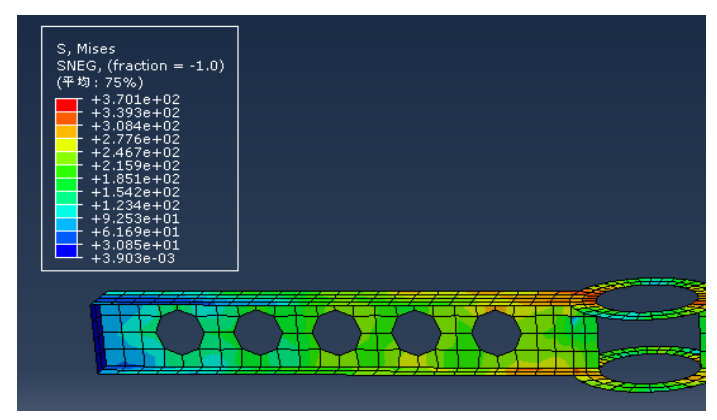

(d) Stress nephogram of the SCB at point D

Figure 7. Stress nephogram of the SCB and the outer annular-stiffener corresponding to the different points of the P- $\Delta$ curve

\section{ACKNOWLEDGEMENTS}

This work was financially supported by China Postdoctoral Science Foundation funded project and Beijing Postdoctoral Research Foundation

\section{REFERENCES}

[1] Han Linhai. Theory and practice of structure of concrete filled steel tube [M]. Beijing: Science Press , 2007. (In Chinese)

[2] ZhaXiaoxiong.Structure of hollow and solid concrete filled steel tube[M]. Beijing: Science Press, 2011. (in Chinese)

[3] Jiang Jie. Nonlinear FEM Analysis on Mechanical Behavior of Joint of Gangue Concrete Filled Steel Tubular Column-Steel Beam under Reversed Low Cyclic Loads[D]. Shenyang: Shenyang Jianzhu University, 2011

[4] El-Din A H M, Mahmoud M H, El-Din F T S ,"Behavior of a concrete-filled steel tube beam-column T-joint" ,Proceedings of the Institution of Civil Engineers, vol. 164, 2011, pp. 229-238.

[5] Kido M., "Flexural strength of beam web to concrete filled circular steel tubular column joints ",Journal of Structural and Construction Engineering,Vol.77 ,2012,pp.483489

[6] Li Guochang, Sun Wei, "Experiment on Middle Joints of Gangue Concrete-Filled Steel Tubes with Ring Stiffeners under Reversed Low Cyclic Loads", Journal of Shenyang Jianzhu University,Vol. 24,2008,pp. 200-203

[7] Li Guochang, Jiang Jie, Jiang Qifeng and Li Shujie, "Nonlinear FEM Analysis on Seismic Performance of Beam to Gangue Concrete Filled Steel Tubular Column Joints under Reversed Low Cyclic Loads", Journal of Shenyang Jianzhu University. Vol. 27,2011,pp. 260-265

[8] Huang Xing, Shi Wenlong,Ye Zhiming"Moment-Rotation Relation Research on Beam-to-Column Composite Joints", Progress in Steel Building Structures, Vol.12,2010, pp. 13-22

[9] Wang Wenda, Qin Geng, Zhang Pengpeng, "Design Approach on Flexural Load-carrying Capacity of Steel Beam to CFST Column Joints with External Stiffening Ring”, Journal of Civil, Architectural \& Environmental Engineering,Vol.33 ,2011, pp. 29-34

[10] Li Ming, Liu Yong, "Research on Steel Beam-column Joints of Concrete Filled Steel Tube",Mechanics and Materials, Vol.166,2012, pp. 43-47

[11] Kim I G, Chung C H and Shim C S"Stress concentration factors of $\mathrm{N}$-joints of concrete-filled tubes subjected to axial loads", Inter- national Journal of Steel Structures, Vol. 14,2014,pp. 1-11 